\title{
Level of satisfaction and its predictors among joint and nuclear family systems in District Abbottabad, Pakistan
}

\author{
Fahad Saqib Lodhi ${ }^{1,2}$, Adeel Ahmed Khan ${ }^{2}$, Owais Raza ${ }^{1}$, Tabrez Uz Zaman ${ }^{3}$, Umer Farooq ${ }^{4}$, \\ Kourosh Holakouie-Naieni*1
}

\begin{abstract}
Background: Family system has been found to affect the satisfaction level among the family members. The objective of our study was to determine the satisfaction level and its predictors among joint and nuclear family systems in District Abbottabad, Pakistan.

Methods: We conducted a population-based cross-sectional study in all 52 Union Councils (UCs) of District Abbottabad, Khyber Pakhtunkhwa province, Pakistan from March 2015 to August 2015. Multistage cluster sampling technique was used to select 2063 participants from both nuclear and joint family houses. Proportionate sampling was done for selecting mohalla from each UCs, and then subsequently households from respective mohalla's. Simple random sampling was done for selecting the 18 years and above-aged participant for the study. A structured demographic questionnaire was used to collect information from study participants. Univariate and multivariate logistic regression analysis was done to find out the predictors of satisfaction level among joint and nuclear family systems using SPSS version $20 \mathrm{~A}$ p-value of $<0.05$ was considered as significant.

Results: Level of satisfaction was found to be higher among people living in the joint family system i.e., $87.5 \% \mathrm{v} / \mathrm{s} 81 \%(<0.001)$ compared to the nuclear family system. Multivariate regression analysis of nuclear family system showed that people having higher education level and higher socioeconomic status (SES) were more satisfied as compared to no education \& low SES respectively. While, in the joint family system, only high SES was a significant predictor of satisfaction in the joint family system as compared to low SES

Conclusion: Our study reported a high level of satisfaction among joint and nuclear family systems in Pakistan. High education level and high SES were identified as important predictors of satisfaction among both systems.
\end{abstract}

Keywords: Satisfaction, Predictors, Family system, Pakistan

Conflicts of Interest: None declared

Funding: None

*This work has been published under CC BY-NC-SA 1.0 license.

Copyright $\subseteq$ Iran University of Medical Sciences

Cite this article as: Saqib Lodhi F, Ahmed Khan A, Raza O, Uz Zaman T, Farooq U, Holakouie-Naieni K. Level of satisfaction and its predictors among joint and nuclear family systems in District Abbottabad, Pakistan. Med J Islam Repub Iran. 2019 (24 Jun);33:59. https://doi.org/10.47176/mjiri.33.59

\section{Introduction}

Joint and nuclear family systems have been recognized as well-known family systems worldwide. Urbanization, rapid industrialization, and expansion of education have shifted the family type from joint to nuclear families (1). There are some disadvantages that are associated with joint family type, but it also has many advantages. Joint families usually have considerable assets. They also have better con-

Corresponding author: Dr Kourosh Holakouie-Naieni, holakoik@hotmail.com

1. Department of Epidemiology and Biostatistics, School of Public Health, Tehran University of Medical Sciences, Tehran, Iran

2. Saudi Board Program of Preventive Medicine, Ministry of Health, Makkah AlMukarrama, Kingdom of Saudi Arabia

3. Faculty of Public Health and Health Informatics, Department of Health Information and Technology ,Umm Al-Qura University, Makkah Al-Mukarrama ,Kingdom of Saudi Arabia

4. Community Medicine Department, Ayub Medical College, Abbottabad, Pakistan ditions of living, including like electricity, sanitation facilities, piped water and higher-quality housing materials (24). The assets and living conditions can be shared among all the members of the family. Sometimes, the daily income of each person in a joint family is more than in a nuclear family (5). The level of satisfaction is a matter of concern in nuclear and joint families. It is a broad aspect and can be measured by different parameters. Some of which can be

$\uparrow$ What is "already known" in this topic:

There is scare literature available about the satisfaction of family system among Pakistani general population.

$\rightarrow$ What this article adds:

Our study reported a high level of satisfaction among joint and nuclear family systems in Pakistan. High education level and high SES were identified as important predictors of satisfaction among both systems. 
better economic condition, better health of a young married woman, better agreement between the family members, peace of mind, and better understanding. In a joint family setting, the children tend to grow up under the compassionate supervision of parents, grandparents, and other relatives who are elders. There is interaction among diverse age groups. This makes a better mutual understanding, so the adjustment problems are fewer (6). There is an added advantage in joint families, which is normally attributed to more bread earners and thereby pooling of more resources and labor. This can increase the gross annual income and can reduce consumption costs. In joint families, it may be difficult for the husband to buy special foods for his wife as it is normally shared between the family members. This can affect the maternal health when she is pregnant, or she is a nursing mother (7). But at the same time, the mother-in-law in joint families can be a great help to the daughter-in-law, especially when she is pregnant as she will do most of the household chores (8). The joint family system is mostly found in the Asian subcontinent, particularly in Pakistan, India, and Bangladesh.

The marital adjustment in women from nuclear families is greater than in joint families. Another aspect of joint families is that the daughter-in-law has a limited say in the decision-making of the families. But the effectiveness of joint families cannot be taken out of consideration because there is a joint responsibility in these families, which gives an edge over in times of hardships and difficulties in life (9). The above points can directly or indirectly affect the satisfaction level in nuclear and extended families.

This study was an attempt to find out the level of satisfaction in nuclear and extended families keeping in mind the various advantages and disadvantages associated with both types of families.

The objective of our study was to determine the satisfaction level among nuclear and joint families in District Abbottabad. Furthermore, we also wanted to find out the predictors of satisfaction for joint and nuclear family systems.

\section{Methods}

\section{Study design}

We conducted a population-based cross-sectional study in all 52 Union Councils of District Abbottabad, Khyber Pakhtunkhwa province, Pakistan from March 2015 to August 2015. We recruited 2063 participants for our study, as this was part of the larger project that has been discussed in another article (10). Briefly, describing, the district is divided into two Tehsils (administrative areas) namely-Abbottabad and Hevellian which comprises of fifty-two Union Councils. District Abbottabad has an area of 1967 sq. km, with a population of 8,81,000 and an average annual growth rate of $1.82 \%(11)$. The overwhelming majority of Abbottabad's population (99\%) is Muslim, and religion exercises a significant influence on daily life. The primary language spoken here is Hindko (used by $94 \%$ of the rural population and $75 \%$ of urban residents) with Punjabi, Pashto, and Urdu being spoken and understood in urban areas. Abbottabad's social structure is heavily influenced by tribal affiliations. Most of the district's residents belong to the Abbassi, Dhund, Gujjar, Jadoon, Karlal, Syed, or Tanoli tribes (11).

\section{Recruitment}

The subjects of our study were randomly selected from both nuclear and joint family houses from all union councils of District Abbottabad, Pakistan. The inclusion criteria used for selection were age greater than 18 years and permanent resident of union council for at least 5 years. Guests and temporary residents were excluded from the study.

Multi-stage cluster sampling technique was employed in this study. Each union council was further divided into several further blocks in the shape of Mohallah. We did proportionate sampling according to the 1998 census population (12) of UCs for the selection of Mohallah \& on the next stage households. In the first stage, we randomly selected these blocks (Mohallah) by using simple random sampling technique. In the next stage, we choose a number of households in that selected block by using a random sampling technique again. The total number of houses selected in each union council were proportional to the population size of the respective union council. A simple random sampling technique was used for the selection of person ( $\geq 18$ years) from each house. Simple random sampling was done by applying the lottery method for selecting the $\geq 18$ year's participant for the study. One day training session was conducted for administering the questionnaires prior to data collection for lady health workers of all UCs by the principal investigator. The questionnaire was administered face to face by trained lady health workers of that union council.

\section{Data collection}

We used a structured demographic questionnaire which included variables such as age, gender, marital status (married, never married), type of family (joint and nuclear), Residence type (urban and rural), residence ownership (owner, not owner), respondent education (no education, madrassa, can read/write, primary- up to grade 5 , secondary education-up to grade 12 and tertiary-up to grade 16 or above), working status (employed, unemployed and retired) and presence of any disease. The satisfaction of the family system was assessed on a Likert scale [from 1 (strongly satisfaction) to 5 (strongly dissatisfaction)], to satisfied and unsatisfied.

The Socio-economic characteristics were assessed by taking household conditions, sources of drinking water, sanitation facilities, availability of electricity, housing facilitates, possession of durable goods, mean of transport, inventory of household and personal items such as chairs, clocks, buckets, radios, television sets, fans, stoves or cookers, cars, and telephones. This list was composed of 21 such items used in Pakistan demographic and health survey in 2013 (13). Wealth index was measured by an index constructed from principal component analysis (PCA) of items indicating ownership of household durables and dwelling characteristics. PCA is a multivariate statistical technique used to reduce the number of variables in a data set into a smaller number of dimensions (14).

\section{Ethics}

This study was approved by the Ethics Committee of Tehran University of Medical Sciences and by health and 
political-administrative bodies of Abbottabad District, Pakistan. All participants provided verbal and written consent prior to the interview.

\section{Data analysis}

Analysis was performed using SPSS version 21.0. Frequencies and percentages were reported for categorical variables while mean and standard deviation for continuous variables were calculated. To enhance interpretability, we recoded our outcome variable satisfaction level of the family system on Likert scale [from 1 (strongly satisfaction) to 5 (strongly dissatisfaction)], to satisfied and unsatisfied. The covariates were sex, marital status, education, type of residence, residence ownership, socio-economic status, working status, and respondent's health. Univariate analysis was done to find the unadjusted association of covariates with the satisfaction level of family systems. The variables that came out significant in the univariate model (p-value $<0.25$ ) and those who had biological plausibility were entered in the final model. Multiple logistic regression analysis was done to generate adjusted odds ratios with their $95 \%$ confidence intervals to assess the relationship of respondents' satisfaction with all study variables. P-value of $<0.05$ was considered as significant. Chi-square test was applied to see the difference in the satisfaction of family system among both joint and nuclear family systems.

\section{Results}

Demographic characteristics of our study participants are shown in (Table 1). Out of 2063 study participants, 1050 $(50.1 \%)$ belonged to the joint family system and 1010 $(49.9 \%)$ to the nuclear family. Larger percentage of people aged between 18 to 30 years $(39.2 \%)$ in the joint family and $(35.4 \%)$ between age group 31 to 40 years in the nuclear family system. Approximately $52 \%(\mathrm{n}=553)$ respondents were male in joint families and $50 \%(n=505)$ in nuclear families. Majority of the subjects $(32.6 \%)$ were an education level up to grade 1(Primary) in joint family and $(33.3 \%)$ up to grade 2 (secondary) in the nuclear family system.

Table 2 is presenting a level of satisfaction among joint and nuclear family system; satisfaction level was found to be statistically significant $(<0.001)$, higher among people living in the joint family group, i.e. $87.5 \%$ and $81 \%$ in the nuclear family system respectively.

Results of Univariate and Multivariate logistic regression analysis of satisfaction in nuclear family system are presented in Table 3. In univariate analysis, people living in their own houses were 1.63 times more likely to be satisfied as compared to people who were not living in their own houses. Compared with people having no education, madrassa education were found to be 6.62 times, secondary education 3.06 times, primary education 2.50 times, can

Table 1. Demographic characteristic of study participants in District Abbottabad, Pakistan (n=2063)

\begin{tabular}{|c|c|c|c|}
\hline S. No. Parameter & $\begin{array}{c}\text { Joint Family System } \\
(\mathrm{n}=1,053)\end{array}$ & $\begin{array}{l}\text { Nuclear Family System } \\
(\mathrm{n}=1010)\end{array}$ & $\begin{array}{c}\text { Total } \\
(\mathrm{n}=2063)\end{array}$ \\
\hline Type of family & $1,053(51.04 \%)$ & $1,010(48.96 \%)$ & 2063 \\
\hline \multicolumn{4}{|l|}{ Age } \\
\hline$<=30$ year & $412(39.2 \%)$ & $308(20.6 \%)$ & $720(34.9 \%)$ \\
\hline $31-40$ & $277(26.3 \%$ & $359(35.4 \%)$ & $636(30.8 \%)$ \\
\hline $41-50$ & $149(14.2 \%)$ & $240(23.7 \%)$ & $389(18.8 \%)$ \\
\hline$>50$ & $215(20.4 \%)$ & $103(10.2 \%)$ & $318(15.4 \%)$ \\
\hline \multicolumn{4}{|l|}{ Sex } \\
\hline Males & $553(52.5 \%)$ & $505(50.0 \%)$ & $1058(51.2 \%)$ \\
\hline Females & $500(47.5 \%)$ & $505(50.5 \%)$ & $1005(48.7 \%)$ \\
\hline \multicolumn{4}{|l|}{ Marital Status } \\
\hline Married & $843(80.0 \%)$ & $796(78.8 \%)$ & $1639(79.4 \%)$ \\
\hline Single & $165(15.6 \%)$ & $184(18.2 \%)$ & $349(16.9 \%)$ \\
\hline \multicolumn{4}{|l|}{ Education } \\
\hline No education & $163(15.4 \%)$ & $159(15.7 \%)$ & $322(15.6 \%)$ \\
\hline Madrassa & $17(1.6 \%)$ & $30(2.9 \%)$ & $47(2.2 \%)$ \\
\hline Can read / write & $111(10.5 \%)$ & $100(9.9 \%)$ & $211(10.2 \%)$ \\
\hline Primary (up to grade 1) & $342(32.6 \%)$ & $295(29 \%)$ & $637(30.8 \%)$ \\
\hline Secondary (up to grade 2) & $321(30.4 \%)$ & $337(33.3 \%)$ & $658(31.8 \%)$ \\
\hline Tertiary (up to grade 3 ) & $97(9.2 \%)$ & $91(9 \%)$ & $188(9.1 \%)$ \\
\hline \multicolumn{4}{|l|}{ Place of Residence } \\
\hline Urban & $297(28.3 \%)$ & $301(29.5 \%)$ & $598(29 \%)$ \\
\hline Rural & $753(71.7 \%)$ & $712(70.5)$ & $1465(71 \%)$ \\
\hline \multicolumn{4}{|l|}{ Residence Ownership } \\
\hline Owner & $989(94.2 \%)$ & $884(87.5 \%)$ & $1873(77.5 \%)$ \\
\hline Not Owner & $61(5.8 \%)$ & $126(12.5 \%)$ & $187(22.5 \%)$ \\
\hline \multicolumn{4}{|l|}{ Working status } \\
\hline Not working & $397(37.7 \%)$ & $413(40.9 \%)$ & $810(39.3 \%)$ \\
\hline Working & $595(56.5 \%)$ & $567(56.1 \%)$ & $1162(56.3 \%)$ \\
\hline Retired & $61(5.8 \%)$ & $30(3 \%)$ & $91(4.4 \%)$ \\
\hline \multicolumn{4}{|l|}{ Socioeconomic Status } \\
\hline High & $391(37.1 \%)$ & $296(29.3 \%)$ & $687(33.3 \%)$ \\
\hline Average & $374(35.6 \%)$ & $312(31.9 \%)$ & $690(33.4 \%)$ \\
\hline Low & $287(27.3 \%)$ & $399(39.5 \%)$ & $686(33.3 \%)$ \\
\hline \multicolumn{4}{|l|}{ Respondent Disease } \\
\hline Ill & $615(58.6 \%)$ & $602(59.60 \%)$ & $1217(59.07 \%)$ \\
\hline Healthy & $435(4.4 \%)$ & $408(40.4 \%)$ & $843(740.9 \%)$ \\
\hline
\end{tabular}




\begin{tabular}{lccc}
\multicolumn{4}{l}{ Table 2. Level of satisfaction among joint and nuclear type of family system in district Abbottabad, Pakistan $(\mathrm{n}=2063)$} \\
\hline Type of Family & Satisfaction & Dissatisfaction & $\mathrm{p}$ \\
\hline Joint & $918(87.5 \%)$ & $133(12.5 \%)$ & $<0.001$ \\
Nuclear & $817(81 \%)$ & $195(19 \%)$ & \\
\hline
\end{tabular}

$\mathrm{read} /$ write 1.64 time and tertiary education were 1.03 times more likely to be satisfied. Compared to low socioeconomic status, respondents having high and moderate SES was 1.44 times and 1.56 times more likely to be satisfied in univariate analysis of the nuclear family system. Rest of the variables like type of residence, gender, age, marital status, and disease were found to be insignificant in univariate analysis.

Multivariate logistic regression analysis of nuclear family system showed that madrassa education were 5.22 times, secondary education 2.13 times, primary education 2.05 times, can read/write 1.64 time and tertiary education were 1.03 times more likely to be satisfied when we compared it with participants having no education. Similarly, respondents having high socioeconomic status were 1.29 times, and average socioeconomic status was 1.76 times more likely to be satisfied when compared to low SES as shown in (Table 3).

Results of Univariate and Multivariate logistic regression analysis of satisfaction in Joint family system are presented in Table 4. In univariate analysis, people living in their own houses were 1.75 times more likely to be satisfied as compared to people who were not living in their own houses. Compared with people having no education, primary education was found to be 1.90 times, secondary education 2.28 times, and tertiary education was 3.38 times more likely to be satisfied. Compared to low socioeconomic status, respondents having high SES had 3.13 times more likely to be satisfied in univariate analysis of the joint family system. Rest of the variables like type of residence, gender, age, marital status, employment status, and disease were found to be insignificant in univariate analysis.

Multivariate analysis of joint family system showed only one variable statistically significant that was high socioeconomic status and it showed 3.46 times more likely to be satisfied when compared it to low socioeconomic status as shown in (Table 4).

\begin{tabular}{|c|c|c|c|c|c|c|c|c|}
\hline \multirow[t]{3}{*}{ Variable } & \multicolumn{4}{|c|}{ Univariate analysis } & \multicolumn{4}{|c|}{ Adjusted analysis } \\
\hline & \multirow[t]{2}{*}{ OR } & \multicolumn{2}{|c|}{$95 \% \mathrm{CI}$} & \multirow[t]{2}{*}{$\mathrm{p}$} & \multirow[t]{2}{*}{ OR } & \multicolumn{2}{|c|}{$95 \% \mathrm{CI}$} & \multirow[t]{2}{*}{$\mathrm{p}$} \\
\hline & & LL & UL & & & LL & UL & \\
\hline \multicolumn{9}{|l|}{ Type of Residence } \\
\hline Rural & \multicolumn{4}{|c|}{$\mathrm{R}$} & \multicolumn{3}{|c|}{$\mathrm{R}$} & \\
\hline Urban & 1.00 & 0.71 & $\begin{array}{l}1.41 \\
\text { Sex }\end{array}$ & 0.979 & 1.41 & 0.91 & 2.20 & 0.125 \\
\hline Female & \multicolumn{4}{|c|}{$\mathrm{R}$} & \multicolumn{3}{|c|}{$\mathrm{R}$} & \\
\hline Male & 1.20 & 0.87 & 1.65 & 0.242 & 1.16 & 0.79 & 1.71 & 0.444 \\
\hline \multicolumn{9}{|l|}{ Residence Ownership } \\
\hline Not Owner & \multicolumn{4}{|c|}{$\mathrm{R}$} & \multicolumn{3}{|c|}{$\mathrm{R}$} & \\
\hline Owner & 1.63 & 1.05 & 2.51 & 0.027 & 1.46 & 0.88 & 2.43 & 0.145 \\
\hline \multicolumn{9}{|l|}{ Respondent Age } \\
\hline$<=30$ year & 1.03 & 0.57 & 1.85 & 0.919 & 1.17 & 0.57 & 2.40 & 0.663 \\
\hline $31-40$ & 0.98 & 0.55 & 1.74 & 0.948 & 1.07 & 0.56 & 2.05 & 0.841 \\
\hline $41-50$ & 0.72 & 0.40 & 1.31 & 0.293 & 0.81 & 0.43 & 1.56 & 0.533 \\
\hline$>50$ & \multicolumn{4}{|c|}{$\mathrm{R}$} & \multicolumn{4}{|c|}{$\mathrm{R}$} \\
\hline \multicolumn{9}{|l|}{ Marital Status } \\
\hline Single & \multicolumn{4}{|c|}{$\mathrm{R}$} & \multicolumn{4}{|c|}{$\mathrm{R}$} \\
\hline Married & 1.07 & 0.73 & 1.57 & 0.705 & 1.18 & 0.71 & 1.94 & 0.521 \\
\hline \multicolumn{9}{|l|}{ Education } \\
\hline No Education & \multicolumn{4}{|c|}{$\mathrm{R}$} & \multicolumn{4}{|c|}{$\mathrm{R}$} \\
\hline Madressa & 6.62 & 1.51 & 28.91 & 0.021 & 5.22 & 1.17 & 23.37 & 0.031 \\
\hline Can read / write & 1.64 & 0.92 & 2.90 & 0.088 & 1.54 & 0.85 & 2.80 & 0.154 \\
\hline Primary & 2.50 & 1.59 & 3.93 & $<0.001$ & 2.05 & 1.25 & 3.25 & 0.004 \\
\hline Secondary & 3.06 & 1.94 & 4.81 & $<0.001$ & 2.13 & 1.29 & 3.52 & 0.003 \\
\hline Tertiary & 1.03 & 1.04 & 3.57 & 0.035 & 1.23 & 0.62 & 2.44 & 0.561 \\
\hline Disease & & & & & & & & \\
\hline ILL & & & & & & & & \\
\hline HEALTHY & 1.36 & 0.93 & 1.99 & 0.11 & 1.05 & 0.74 & 1.49 & 0.801 \\
\hline Employment status & & & & & & & & \\
\hline Not Working & & & & & & $\mathrm{R}$ & & \\
\hline Working & 2.53 & 0.67 & 9.55 & 0.169 & 1.08 & 0.73 & 1.59 & 0.709 \\
\hline Retired & 1. 26 & 0.49 & 3.41 & 0.641 & 1.22 & 0.46 & 3.86 & 0.592 \\
\hline Socioeconomic status & & & & & & & & \\
\hline Low & & & & & & & & \\
\hline Average & 1.81 & 1.25 & 2.62 & $<0.002$ & 1.76 & 1.18 & 2.63 & 0.006 \\
\hline High & 3.37 & 2.17 & 5.25 & $<0.001$ & 3.70 & 2.23 & 6.14 & $<0.001$ \\
\hline
\end{tabular}

${ }^{\mathrm{a} R}$., reference

Abbreviations: OR, odds ratio, CI, confidence interval;

Adjusted analysis performed with all variables entered simultaneously into the model 
Table 4. Predictors of satisfaction in joint family system in district Abbottabad, Pakistan $(\mathrm{n}=1053)$

\begin{tabular}{|c|c|c|c|c|c|c|c|c|}
\hline \multirow[t]{3}{*}{ Variable } & \multicolumn{4}{|c|}{ Univariate analysis } & \multicolumn{4}{|c|}{ Adjusted analysis } \\
\hline & \multirow[t]{2}{*}{ OR } & \multicolumn{2}{|c|}{$95 \%$ CI } & & \multirow[t]{2}{*}{ OR } & \multicolumn{2}{|c|}{$95 \% \mathrm{CI}$} & \\
\hline & & LL & UL & & & LL & UL & \\
\hline \multicolumn{9}{|c|}{ Type of Residence } \\
\hline Rural & \multicolumn{4}{|c|}{$\mathrm{R}$} & \multicolumn{3}{|c|}{$\mathrm{R}$} & \\
\hline Urban & 1.07 & 0.71 & $\begin{array}{l}1.59 \\
\text { Sex }\end{array}$ & 0.737 & 1.46 & 0.90 & 2.37 & 0.126 \\
\hline Female & \multicolumn{4}{|c|}{$\mathrm{R}$} & \multicolumn{3}{|c|}{$\mathrm{R}$} & \\
\hline Male & 1.47 & 1.02 & 2.13 & 0.037 & 1.35 & 0.67 & 2.70 & 0.124 \\
\hline \multicolumn{9}{|c|}{ Residence Ownership } \\
\hline Not Owner & \multicolumn{4}{|c|}{$\mathrm{R}$} & \multicolumn{3}{|c|}{$\mathrm{R}$} & \\
\hline Owner & 1.75 & 0.95 & 3.24 & 0.072 & 1.35 & 0.67 & 2.70 & 0.400 \\
\hline \multicolumn{9}{|l|}{ Respondent Age } \\
\hline$<=30$ year & 0.89 & 0.54 & 1.47 & 0.673 & 0.73 & 0.40 & 1.34 & 0.313 \\
\hline $31-40$ & 1.43 & 0.80 & 2.56 & 0.222 & 1.26 & 0.66 & 2.43 & 0.487 \\
\hline $41-50$ & 0.70 & 0.38 & 1.26 & 0.241 & 0.71 & 0.37 & 1.35 & 0.293 \\
\hline$>50$ & \multicolumn{4}{|c|}{$\mathrm{R}$} & \multicolumn{4}{|c|}{$\mathrm{R}$} \\
\hline \multicolumn{9}{|l|}{ Marital Status } \\
\hline Single & \multicolumn{4}{|c|}{$\mathrm{R}$} & \multicolumn{4}{|c|}{$\mathrm{R}$} \\
\hline Married & 0.99 & 0.954 & 0.62 & 0.954 & 0.85 & 0.51 & 1.39 & 0.511 \\
\hline \multicolumn{9}{|l|}{ Education } \\
\hline No Education & \multicolumn{4}{|c|}{$\mathrm{R}$} & \multicolumn{4}{|c|}{$\mathrm{R}$} \\
\hline Madressa & 1.80 & 0.39 & 8.33 & 0.456 & 1.40 & 0.29 & 6.84 & 0.678 \\
\hline Can read/write & 1.42 & 0.74 & 2.71 & 0.284 & 1.37 & 0.69 & 2.72 & 0.369 \\
\hline Primary & 1.90 & 1.15 & 3.15 & 0.012 & 1.44 & 0.82 & 2.55 & 0.206 \\
\hline Secondary & 2.28 & 1.34 & 3.85 & 0.002 & 1.57 & 0.85 & 2.90 & 0.147 \\
\hline Tertiary & 3.38 & 1.43 & 7.99 & 0.005 & 1.78 & 0.69 & 4.59 & 0.233 \\
\hline \multicolumn{9}{|l|}{ Disease } \\
\hline Ill & \multicolumn{4}{|c|}{$\mathrm{R}$} & & & & \\
\hline Healthy & 1.36 & 0.93 & 1.99 & 0.112 & 1.39 & 0.93 & 2.08 & 0.112 \\
\hline Employment sta & & & & & & & & \\
\hline Not Working & & & & & & $\mathrm{R}$ & & \\
\hline Working & 1.45 & 1.00 & 2.12 & 0.051 & 0.91 & 0.57 & 1.45 & 0.678 \\
\hline Retired & 1. 17 & 0.53 & 2.59 & 0.688 & 0.89 & 0.37 & 2.12 & 0.786 \\
\hline Socioeconomic s & & & & & & & & \\
\hline Low & & & & & & & & \\
\hline Average & 1.44 & 0.95 & 2.18 & 0.084 & 1.46 & 0.93 & 2.27 & 0.094 \\
\hline High & 3.13 & 1.91 & 5.11 & $<0.001$ & 3.46 & 1.95 & 6.11 & $<0.001$ \\
\hline
\end{tabular}

${ }^{a} \mathrm{R}$., reference

Abbreviations: OR, odds ratio, CI, confidence interval;

Adjusted analysis performed with all variables entered simultaneously into the model

\section{Discussion}

Family is considered as the main source of caregiving to all its members. The family system is prominent in Pakistani culture, and people love to give proper value to their family systems. Strong cultural heritage has become part of their lifestyle for decades. It plays a vital role in the daily life of the people which affects their decision making, social role, and profession. Joint family system was the most accepted type of family since the time of partition, but with the passage of time and result of industrialization and the subsequent urbanization reasoned the divergence towards the nuclear family system $(15,16)$.

Our study was conducted to find out the level of satisfaction in nuclear and joint family systems and also to find out the predictors in both types of family systems in District Abbottabad, Pakistan. The individuals who live in joint families have to deal with different expectations than individuals who live in nuclear families. It was generally believed that those individuals who live in a joint family situation would have to face greater restrictions and fewer independent choices, as a result, would have lesser satisfaction levels. The experience of autonomy would be higher in a nuclear family since the members would be acting out of their own volition without regard to specific family dynamics and would be enjoying more satisfaction levels. In our study, level of satisfaction was found to be higher among people living in the joint family group, i.e. $87.5 \% \mathrm{v} / \mathrm{s} 81 \%$ in the nuclear family $(<0.001)$ (Table 2$)$. We observed that the satisfaction level was overall high in both types of family systems. Similar results were found in a study conducted in Karachi, Pakistan by Itrat et al. which concluded that almost $96 \%$ of people were satisfied in joint family and $85 \%$ in the nuclear family system (17). A study conducted in Islamabad, Rawalpindi and Wah Cantt, Pakistan showed similar findings where people living in joint family system has significantly higher social support and quality of life $(\mathrm{p}<0.001)$ as compared to people living in a nuclear family (18). Possible reasons for having high satisfaction level among people living in the joint family system were spending quality time with other family members, strong bonding network, stable and durable connection, division of labor and in times of crises and emergencies support from other members of joint family. Being an Islamic country, it is also presumed that children's should take care of their elders in the same way their elders took care of them in their childhood. Whereas, living in nuclear family system benefits in the shape of sense of freedom to live according to their 
wishes, more involvement in decision making, giving maximum time to their children and complete privacy available to them.

Our analysis showed that higher education and high socioeconomic status were the most significant predictors of satisfaction in the nuclear family system (Table 3). However, other study claimed as both family systems have a significant relation with the academic achievements as both, nuclear and joint family systems, effects on the academic achievements of the students (19). Possible reasons behind our results were having the quality time given to their children's by parents in the nuclear family system, help in their school/college work, taking maximum care during their studies time results in better outcomes. On the contrary, few studies have found insignificant relation between the type of family and academic achievement (20).

Socioeconomic status was also the important predictor of the level of satisfaction in both joint and nuclear family systems after multivariate analysis. Being wealthy and having higher socioeconomic status has been associated with more satisfaction for both family types. As owning more assets will result in having improved living conditions, quality houses, and proper sanitation facilities (21). That will eventually translate in better satisfaction levels.

The study has several strengths to be reported. It is the first of its kind in Pakistan, which has reported the level of satisfaction among both types of family systems. Participants in joint families had higher satisfaction than those in nuclear families. And this may be due to Pakistani cultural effect. Our study adopted robust multi-stage sampling technique and took a representative sample from District $\mathrm{Ab}$ bottabad, which is one of its major strengths. Finally, the data was collected using a structured questionnaire adapted from other studies in similar settings.

There were also limitations in this study which needs to be considered. The outcome measure used in our study consisted of one question on Likert scale, which is major limitation, and that would influence the internal validity of our work. We think that a more robust composite measure of satisfaction could be used in future studies to further explore this subjective phenomenon of satisfaction level. This was a cross-sectional study, and temporal associations could not be ascertained with certainty, and we cannot say surely whether the predictors of our study preceded the level of satisfaction.

\section{Conclusion}

This study was the first evidence regarding satisfaction level among joint and nuclear family systems in Pakistan, reporting a high level of satisfaction among both groups. High education level and high SES were identified as important predictors of satisfaction among both systems.

\section{Acknowledgments}

FSL, OR, AAK, UF, KHN conceived, designed and did statistical analysis, editing \& critical review of the manuscript. FSL did data collection. FSL, TZ, and AAK did manuscript writing. FSL, UF, KHN did review, drafting, and final approval of the manuscript.
Conflict of Interests

The authors declare that they have no competing interests.

\section{References}

1. Adams BN. Themes and threads of family theories: A brief history. J Comp Fam Stud. 2010;41:499-505.

2. Gage AJ, Sommerfelt AE, Piani AL. Household structure, socioeconomic level, and child health in sub-Saharan Africa (Demographic and Health Surveys Analytical Reports No. 1). Calverton, MD: Macro International Inc. 1996.

3. Mberu BU. Household structure and living conditions in Nigeria. J Marriage Fam. 2007;69:513-527.

4. Niranjan S, Nair S, Roy TK. A socio-demographic analysis of the size and structure of the family in India. J Comp Fam Stud. 2005;36:623651.

5. Murthy PSN, Ramnath T, Vijayaraghavan, K, Rao NP. Nutritional profile of joint and nuclear families in rural Andhra Pradesh. J Fam Welfare. 1985;32:80-87.

6. Nagaraja, A, Rajamma N M, Reddy SV. Effect of Parents' Marital Satisfaction, Marital Life Period and Type of Family on their Children Mental Health Status. J Psychology. 2017;3(2):65-70.

7. Jeffrey P, Jeffrey R, Lyon A. Labour Pains and Labour Power: Women and Childbearing in India. London: Zed Books; 1989.

8. Ellsberg M, Jansen, HA, Heise L, Watts CH, Garcia-Moreno C. Intimate partner violence and women's physical and mental health in the WHO Multi-Country Study on Women's Health and Domestic Violence: An observational study. Lancet. 2008;371:1165-1172.

9. Sabre K. Marital adjustment among women: A comparative study of nuclear and joint families. Int J Indian Psychol. 2016;3(2):26-32.

10. Saqib Lodhi F, Raza O, Montazeri A, Nedjat S, Yaseri M, HolakouieNaieni K. Psychometric properties of the Urdu version of the World Health Organization's quality of life questionnaire (WHOQOL-BREF). Med J Islam Repub Iran. 2017;31:129.

11. Earthquake Reconstruction and Rehabilitation Authority Prime Minister's Secretariat I. District Profile - Abbottabad. 2007, p. vii

12. Haq M, Mustafa U, Ahmad I. Household's willingness to pay for safe drinking water: a case study of Abbottabad district. The Pakistan Development Review. 2007;46(4):1137-53

13. http://www.nips.org.pk/abstract files/PDHS\%20Final\%20Report $\% 20$ as $\% 20$ of $\% 20 \mathrm{Jan} \% 2022-2014$.pdf.

14. Vyas S, Kumaranayake L. Constructing socio-economic status indices: how to use principal components analysis. Health Policy Plan. 2006;21(6):459-468.

15. Agarwala BR. Nature and extent of social change in a mobile commercial community. Sociol Bull. 1962;11.

16. Chen M, Drèze J. Widows and Health in Rural North India. Econ Political Wkly. 1992;27(43-44):24-31.

17. Itrat A, Taqui AM, Qazi F, Qidwai W. (2007). Family systems: perceptions of elderly patients and their attendants presenting at a university hospital in Karachi. JPMA. 2007;57(2):106-109.

18. Naz S, Naz S, Gul S. Relationship between Economic Independence, Social Support and Quality of Life among Elderly People. J Indian Acad App Psychol. 2014; 40: 255.

19. Bilal HA, Tariq AR, Aleem U, Shabir SI, Perveen M. The effects of nuclear and joint family systems on academic achievement of students. Acad Res Inter. 2013;5(4):543-549.

20. Maharishi R, Parameswari J. Influence of Emotional Intelligence on Study Involvement among Adolescents. IJEPR. 2013;2(4): 30-36.

21. Jeffery R, Jeffery P. Population, Gender and Politics: Demographic Change in Rural North India. Cambridge: Cambridge University Press. 1997. 